ORIGINAL RESEARCH ARTICLE

\title{
How do medium naturalness and personality traits shape academic achievement and perceived learning? An experimental study of face-to-face and synchronous e-learning
}

\author{
Ina Blau*, Orli Weiser and Yoram Eshet-Alkalai \\ Department of Education and Psychology, The Open University of Israel, Ra'anana, Israel
}

(Received 16 February 2017; final version received 16 May 2017)

\begin{abstract}
This controlled experiment examined how academic achievement and cognitive, emotional and social aspects of perceived learning are affected by the level of medium naturalness (face-to-face, one-way and two-way videoconferencing) and by learners' personality traits (extroversion-introversion and emotional stabilityneuroticism). The Media Naturalness Theory explains the degree of medium naturalness by comparing its characteristics to face-to-face communication, considered to be the most natural form of communication. A total of 76 participants were randomly assigned to three experimental conditions: face-to-face, one-way and two-way videoconferencing. E-learning conditions were conducted through Zoom videoconferencing, which enables natural and spontaneous communication. Findings shed light on the trade-off involved in media naturalness: one-way videoconferencing, the less natural learning condition, enhanced the cognitive aspect of perceived learning but compromised the emotional and social aspects. Regarding the impact of personality, neurotic students tended to enjoy and succeed more in face-to-face learning, whereas emotionally stable students enjoyed and succeeded in all of the learning conditions. Extroverts tended to enjoy more natural learning environments but had lower achievements in these conditions. In accordance with the 'poor get richer' principle, introverts enjoyed environments with a low level of medium naturalness. However, they remained focused and had higher achievements in the face-to-face learning.
\end{abstract}

Keywords: medium naturalness theory; the 'poor get richer' approach; synchronous e-learning; learning achievement; cognitive; emotional and social perceived learning

\section{Introduction}

In recent years, alongside the expansion of technologies used for communication and collaborative learning, synchronous and asynchronous e-learning have become a central part of teaching and learning processes in academia (Selwyn 2014). E-learning is defined as 'instruction delivered on a digital device (such as a desktop computer, laptop computer, tablet, or smartphone) that is intended to support learning' (Clark and Mayer 2016, p. 8). E-learning is conducted in digital environments in the form of speech or text and images such as pictures, illustrations, graphs, videos or animations. According to Clark and Mayer (2016), asynchronous e-learning, which is typically selfpaced and designed for individual studies, continues to be the most prevalent form of

*Corresponding author. Email: inabl@openu.ac.il 


\section{Blau et al.}

e-learning. The main advantage of asynchronous environments is that they are available to learners at any time and location. In contrast, synchronous e-learning is designed for real-time learning or training, facilitated by instructors (e.g. virtual classrooms or webinars). Although synchronous sessions are usually recorded and thus, are also available for asynchronous learning, the main strength of synchronous e-learning lies in the real-time interactions it enables between the instructor and students and among peers.

In the past, because of technological limitations, e-learning was conducted mainly asynchronously or synchronously via one-way videoconferencing, enabling students to watch the lecturer without seeing each other and without the lecturer being able to see them (Mader and Ming 2015; Marquart et al. 2016; Weiser, Blau, and Eshet-Alkalai 2016). Nonetheless, in recent years, synchronous technologies enable real-time interpersonal interactions in cyberspace that create a social environment based on online infrastructure (Barak and Suler 2008; Canto, Jauregi and van den Bergh 2013). With the availability of innovative technologies for synchronous e-learning, the difference between online and face-to-face learning has become blurred, and the gap between the two learning modes (face-to-face and online) which was previously found in students' achievements is decreasing (Kuo 2016; Redpath 2012). This change calls for a reexamination of the suitability of traditional pedagogical paradigms for e-learning. In this context, it is necessary to address the differences between the different types of synchronous learning conditions (e.g. one-way and two-way videoconferencing), and to examine their implications for both teaching and learning.

The current study examined the extent to which the academic achievement and perceived learning of adult learners in general, and of higher education students in particular, are influenced by (1) the learning medium (face-to-face learning vs. synchronous e-learning through one-way and two-way videoconferencing) and (2) students' personality traits (extroversion-introversion and emotional stability-neuroticism), which are reported in the literature as relevant to online interactions and to academic achievement in online environments (Amichai-Hamburger 2005, 2007; Blau and Barak 2011, 2012).

\section{Literature review}

The Media Naturalness Theory (MNT) (Kock 2005) - sometimes referred to as the Psychobiological Model (Kock 2004) - is one of the leading theories that examine synchronous interactions in a wide range of contexts, such as education (Keller 2013; Paretti, McNair and Holloway-Attaway (2007), knowledge transfer (Baehr 2012; Schwartz 2007) and communication in virtual environments (Klitmøller, Schneider, and Jonsen 2015). MNT explores the degree of naturalness of communication channels by comparing their characteristics to face-to-face communication, which is assumed to have the highest level of naturalness (e.g. Sacco and Ismail 2014). This is in accordance with Darwinian evolutionary principles, according to which face-to-face communication has evolved among mankind over thousands of years and includes a range of social communication cues, such as facial expressions, vocal intonation and body language (Kock 2005; Kock and Garza 2011; Kock, Verville, and Garza 2007). MNT suggests five criteria for assessing the level of media naturalness: (1) co-location in a common physical space, (2) a high level of synchronicity that enables immediate 
and spontaneous responses to stimuli, (3) the possibility of identifying and conveying facial expressions, (4) the possibility of identifying and conveying body language and (5) the possibility of conveying natural speech.

According to MNT, a decline in medium naturalness represents a decline in its resemblance to face-to-face communication. Such a decline typically leads to an increase in the cognitive load imposed on the learner, to greater ambiguity in the conveyed message, and to lower psychological arousal during the interaction - all of which contribute to a decrease in learning effectiveness. In contrast, the higher the degree of media naturalness and resemblance to face-to-face communication, the more effective teaching-learning interactions tend to be (Kock 2005; Kock, Verville, and Garza 2007).

Unlike asynchronous communication, in synchronous communication, parties interact with each other in real time. In the educational context, this enables effective, dynamic and spontaneous teaching-learning interactions between instructor and students and among peers (Kuo 2016). The Zoom application, which was used in the current study, is an innovative, advanced platform for two-way videoconferencing, providing a novel learning experience which highly resembles the classroom learning setting (Weiser, Blau, and Eshet-Alkalai 2016). According to MNT, the rationale for considering two-way videoconferencing technologies such as Zoom to have a high level of media naturalness is based on the similarity between face-to-face and twoway videoconferencing learning environments. Nonetheless, it is important to note that synchronous two-way e-learning differs from face-to-face communication in that participants are not co-located in the same physical space during interactions and thus, some important communication cues may not be conveyed effectively (Canto et al. 2013; Warkentin, Sayeed, and Hightower 1997).

Previous studies examined learning experiences and academic achievement in online learning environments with different levels of media naturalness (Kock and Garza 2011; Hattie 2009; Kock, Verville, and Garza 2007; Redpath 2012). These studies have revealed that despite the potential of online technologies for effective and meaningful learning suggested by MNT, their superiority, compared to the traditional, 'natural', face-to-face learning, is unclear.

Note that MNT differs in several ways from the classical approach to understanding synchronous communication as suggested by the Media Richness Theory (MRT; Daft and Lengel 1984; Daft, Lengel, and Treviño 1987). This theory defines medium richness according to the capability of a medium to (1) provide immediate feedback, (2) transmit verbal and non-verbal communication cues, (3) provide a sense of personalisation and (4) simulate a natural language. Similarly to MNT, MRT assumes that face-to-face communication is the richest medium for transmitting information. However, the characteristics of other communication channels, such as videoconferencing explored in this study, may differ according to the theoretical framework chosen to analyse the medium (MNT vs. MRT). Figure 1 compares the characteristics of face-to-face, one-way videoconferencing and two-way videoconferencing communication based on the criteria of MNT and MRT.

In addition to the differences in the criteria used to analyse the degree of medium richness/naturalness, MNT and MRT differ in their prediction regarding the effect of message complexity on the quality of communication and the degree of communicators' satisfaction (Blau and Caspi 2010). For example, a simple message conveyed in a higher education setting might be 'Notify students about a change in the deadline 


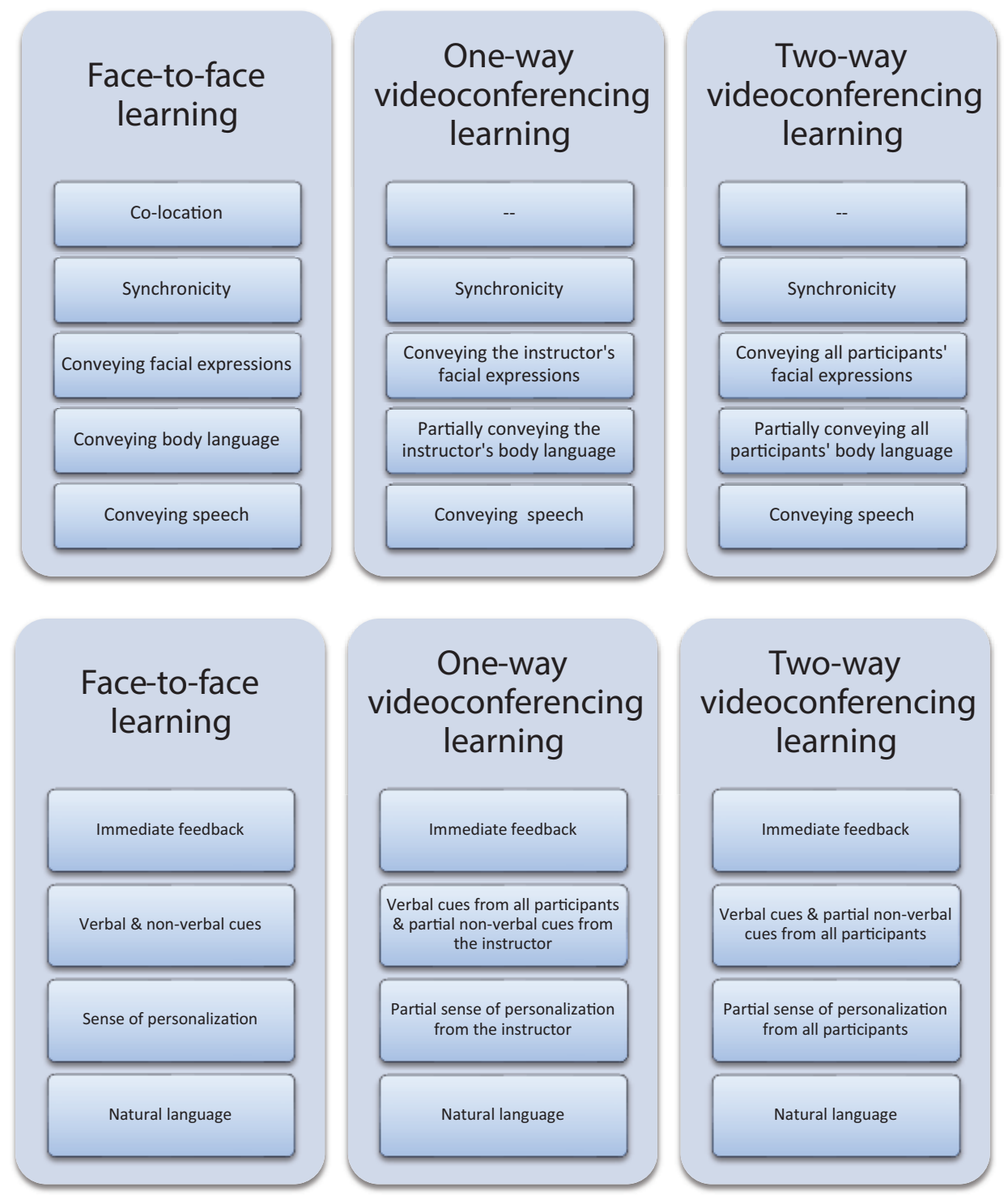

Figure 1. Comparing face-to-face, one-way videoconferencing and two-way videoconferencing in terms of the Media Naturalness Theory (on the top) and the Media Richness Theory (on the bottom).

for handing in an assignment', whereas a complex message might be 'Clarify a complex theoretical issue for a given course unit' (Caspi and Gorsky 2005). MNT assumes that the quality of users' performance and satisfaction depends on inherent characteristics of the medium per se, and are not related to a specific message's attributes. In contrast, MRT distinguishes between the impact of simple versus complex messages, and assumes that a good fit between the message and the medium will result in better performance and higher satisfaction. MRT considers face-to-face communication as the most effective way to convey complex messages, whereas a 'lean medium' is good enough for effectively conveying simple messages. 
Given the divergence between MNT and MRT in relation to the criteria that differentiate media and the role of message complexity, the two theories have different predictions regarding the impact of media and message complexity on learning (Blau and Caspi 2010). Table 1 presents the predictions of both theories regarding message complexity and the three types of media explored in this study. It is reasonable to assume that 'typical' lessons normally convey both simple and complex messages. Therefore, MNT seems to be more promising for evaluating synchronous e-learning in a holistic way - without separating learning outcomes according to the type of instructional messages. Nonetheless, complex messages are the essence of teaching-learning processes. Thus, as Table 1 shows, in the context of this study, MRT predicts that for complex messages, instruction quality/learning outcomes and students' satisfaction will be the highest in face-to-face learning, and the lowest in one-way videoconferencing. In contrast, MNT predicts a similar quality of instruction/learning outcomes in all three types of media, but, similarly to MRT, predicts lower levels of student satisfaction in the less natural medium.

Studies which examined the factors involved in students' learning experiences and academic achievement in synchronous environments have emphasised the pivotal role of personality traits, teaching methods and characteristics of the technology (Blau and Barak 2011; Blau and Caspi 2010; Caspi and Blau 2008; Kock, Verville, and Garza 2007; Kock and Garza 2011). The effect of personality traits on learning achievement in general, and in e-learning in particular, was exemplified by Chang and Chang (2012), who found that when personality traits were added to a multiple regression analysis predicting achievement in e-learning, the overall explained variance increased by $10.6 \%$.

The Big Five Personality Traits Model (Costa and McCrae 1992) is one of the most widely accepted models for describing the role of personality traits in academic contexts (Amichai-Hamburger 2005, 2007; Blau and Barak 2009b). The model consists of five personality traits: extroversion, neuroticism, conscientiousness, openness and agreeableness. The current study focused on extroversion-introversion and emotional stability-neuroticism, which previous studies have found to be relevant to understanding behaviour in online communication in general, and in synchronous online interactions in particular (Amichai-Hamburger 2005, 2007; Amichai-Hamburger

Table 1. Predicting instruction/learning outcomes' quality and satisfaction for different media and messages, based on the Media Naturalness Theory and the Media Richness Theory.

\begin{tabular}{|c|c|c|c|}
\hline Medium & Message & Medium naturalness & Medium richness \\
\hline \multirow[t]{4}{*}{ Face-to-face } & Simple & High-quality outcome & High-quality outcome \\
\hline & & High satisfaction & High satisfaction \\
\hline & Complex & High-quality outcome & High-quality outcome \\
\hline & & High satisfaction & High satisfaction \\
\hline \multirow[t]{4}{*}{ One-way videoconferencing } & Simple & High-quality outcome & High-quality outcome \\
\hline & & Low satisfaction & High satisfaction \\
\hline & Complex & High-quality outcome & Low-quality outcome \\
\hline & & Low satisfaction & Low satisfaction \\
\hline \multirow[t]{4}{*}{ Two-way videoconferencing } & Simple & High-quality outcome & High-quality outcome \\
\hline & & Medium satisfaction & High satisfaction \\
\hline & Complex & High-quality outcome & Medium-quality outcome \\
\hline & & Medium satisfaction & Medium satisfaction \\
\hline
\end{tabular}




\section{Blau et al.}

and Barak 2009; Blau and Barak 2009b, 2011; Maldonado et al. 2001; McKenna, Green and Gleason 2002).

An extrovert is a friendly person, who seeks interpersonal relationships and excitement, is willing to take risks and tends to be impulsive, whereas an introvert is a calm reflective person, who prefers his/her own company and dislikes crowded social events, does not seek excitement and is sometimes perceived by others as being distant (Eysenck and Eysenck 1975). Discussing the role of cyberspace as a compensatory psychological tool, Kraut et al. (2002) claimed that people who easily interact and socialise offline tend to have more friends and social interactions online as well (i.e. 'the rich get richer' principle). Consistent with this principle, studies have found that extroverts tend to feel comfortable in both face-to-face and online environments (e.g. Johnson and Cooke 2015). Other researchers maintain that the 'protective' nature of online environments may help introverts express themselves more freely than in offline, face-to-face interactions ('the poor get richer' principle of Amichai-Hamburger 2005, 2007). According to this principle, while extroverts feel comfortable in both online and offline conditions, introverts tend to feel more comfortable in online environments (McKenna et al. 2007), where they may even adopt extroverted behaviours. While the research literature does not report differences in introverts' and extroverts' academic achievements, introverts have been found to invest more time studying, whereas extroverts tend to spend more time socialising, both offline and online (Blau and Barak 2009a; Voorn and Kommers 2013). Furthermore, although introverts have ideas that may contribute to learning, they often feel uncomfortable expressing them in the face-to-face classroom setting (Blau and Barak 2012).

In contrast to an emotionally stable person, neurotic individuals are described in the literature as worried, restless, and those who tend to have strong emotional responses that are disproportional to the situation (Eysenck and Eysenck 1975). Studies have found that compared to neurotic students, emotionally stable students have higher academic achievements (Chamorro-Premuzic, and Furnham 2003; Furnham, Nuygards, and Chamorro-Premuzic 2013). Furthermore, some studies (for review see: Blau and Barak 2009b) have indicated that compared to emotionally stable students, neurotic students tend to be less satisfied with their academic studies and achievements. It is noteworthy that the majority of studies that have examined the associations between personality traits and academic performance were conducted in traditional rather than online learning environments, emphasising the importance of examining these relations in e-learning settings (Johnson and Cooke 2015).

In order to address the well-established differences between learners' subjective and objective performance evaluations (e.g. Barzilai and Blau 2014; Koriat and Bjork 2005; Rhodes and Castel 2008), in the current study, we compared perceived learning and actual comprehension of the content learned in the lessons. Perceived learning is defined as the set of beliefs and emotions that a person has in relation to the learning process (Caspi and Blau 2008, 2011). Perceived learning is derived both from cognitive and social-emotional sources. A cognitive source is based on the perception that the individual has acquired new knowledge and insights. A socialemotional source reflects the individual's subjective evaluation, namely the experiences and emotions which were involved in the academic interaction with other students and with the instructor. Previous findings (Akyol and Garrison 2014; Caspi and Blau 2008; Lyons, Reysen, and Pierce 2012; Shea et al. 2001) have revealed 
that academic interactions are particularly important in e-learning processes and are positively associated with students' perceived learning.

\section{Research goals and hypotheses}

Teaching via videoconferencing technologies is generally perceived by decisionmakers in higher education (especially in distance learning institutions), as equivalent to face-to-face teaching (Finkelstein 2009). Thus, many academic courses are offered in both face-to-face and two-way/one-way videoconferencing modes. In addition, some courses combine face-to-face teaching with lectures delivered remotely through videoconferencing or audioconferencing. This assumption also guides recent professional training programmes, such as professional development programmes for teachers, which are delivered through videoconferencing or audioconferencing webinars. Surprisingly, despite the expanding practice of substituting face-to-face lessons with videoconferencing-based teaching, few empirical studies have tested its validity, and rigorously compared the educational implications of face-to-face learning to those of learning through two-way videoconferencing (e.g. Weiser, Blau, and EshetAlkalai 2016) or one-way videoconferencing/audioconferencing (e.g. Blau and Caspi 2010; Kock, Verville, and Garza 2007). The current study aims to address this gap in the literature. Specifically, this study was designed to examine the influence of media naturalness (face-to-face learning, two-way videoconferencing and one-way videoconferencing) and personality traits (extroversion-introversion and emotional stability-neuroticism) on learning achievement and perceived learning among students. The following research questions and hypotheses were explored:

(1) How is academic achievement affected by medium naturalness (face-to-face, one-way and two-way videoconferencing) and by participants' personality traits (extroversion-introversion and emotional stability-neuroticism)? The hypotheses were: (a) Naturalness effect: Following the basic assumptions of MNT (Kock 2005), higher scores on the achievement test will be found among students studying in learning environments that have a higher degree of naturalness (i.e. face-to-face learning $>$ two-way videoconferencing $>$ oneway videoconferencing); (b) Personality effect: Based on the literature on personality traits and academic performance (Blau and Barak 2009b, 2011; Amichai-Hamburger and Ben-Artzi 2003; Maldonado et al. 2001; McKenna, Green and Gleason 2002); compared to introverts and neurotic students, extroverts and emotionally stable students will obtain higher scores on the achievement test; and (c) Interaction effect: Personality traits will moderate the media naturalness effect on learning achievement, with the personality effect only found in the face-to-face learning condition.

(2) How are the cognitive, emotional and social aspects of perceived learning affected by the naturalness of the communication medium (face-to-face, oneway and two-way videoconferencing) and by the participants' personality traits (extroversion-introversion and emotional stability-neuroticism)? The hypotheses were that: (a) Naturalness effect: higher levels of perceived learning will be found among students studying in learning environments that have a higher degree of naturalness (i.e. face-to-face learning $>$ two-way videoconferencing $>$ one-way videoconferencing); (b) Personality effect: Compared to introverts 
and neurotic students, extroverts and emotionally stable students will report higher scores on all dimensions of perceived learning; and (c) Interaction effect: Personality traits will moderate the effect of media naturalness on perceived learning, with the personality effect only found in the face-to-face learning condition.

\section{Method \\ Participants}

The sample consisted of 76 native Hebrew speakers, who volunteered to participate in the study. Forty four $(57.9 \%)$ of the participants were women. Participants were recruited from the research participants' repository of the Psychology and Education lab at the Open University of Israel (OUI) and by posting announcements on the OUI's Facebook homepage. Participants' age was not normally distributed (Range: 18-58, Median: 29, Mean: 31.45, SD: 9.835, Skewness: 0.962). Around $69.3 \%$ of the participants were undergraduate students, $9.3 \%$ were graduate students and $21.3 \%$ were not students at the time of the experiment. Around $50.7 \%$ of the participating students were studying social sciences, 13.3\% humanities, $14.7 \%$ exact sciences, and $1.3 \%$ were computer science students. Each participant received a participation fee of 200 NIS (equivalent to approximately 50 US dollars).

\section{Tools and materials}

Communication technology: The research utilised the innovative, intuitive and userfriendly Zoom videoconferencing application that allows large groups of instructors and learners (more than 100 participants) to conduct spontaneous synchronous oneway or two-way educational interactions, in which participants can see and hear each other, using a camera and a microphone (Weiser, Blau, and Eshet-Alkalai 2016). With Zoom, the instructor can easily manage and change the level of interaction and the instruction style during the lesson. Thus, Zoom combines the advantages of face-to-face learning with the benefits of distance learning and can facilitate advanced technology-based pedagogical flexibility.

Personality traits: Based on the Big Five Model (Costa and McCrae 1992), two personality traits, namely extroversion-introversion and emotional stability-neuroticism, were measured in the study using a short Hebrew version of the NEO-PI-R questionnaire (Blau and Barak 2012). As discussed above, according to the research literature, these traits were found to be the most relevant to online learning interactions among the personality traits in the Big Five Model. The extroversion-introversion index was calculated as the average of responses to 12 items (scale 1-6); internal consistency: Cronbach's $\alpha=0.82$ (Range: 2.17-5.50, Median: 4.41, Mean: 4.30, SD: 0.627, Skewness: -0.79). Similarly, the index of emotional stability-neuroticism was calculated as the average of the answers to 12 items (scale 1-6); internal consistency: Cronbach's $\alpha=0.74$ (Range: 1.25-4.58, Median: 3.00, Mean: 3.00, SD: 0.675, Skewness: -0.04). For the purpose of statistical analysis, the participants' dominant personality trait was categorised according to the median of each personality variable. For the extroversion-introversion measure, participants with the median score and below were categorised as introverts. Accordingly, $51.3 \%$ of the participants were categorised as extroverts, and $48.7 \%$ as introverts. For the emotional stability-neuroticism measure, participants with the median score and above were categorised as 
emotionally stable. Accordingly, $47.4 \%$ of the participants were categorised as emotionally stable and $52.6 \%$ as neurotic. A previous study which used the Hebrew version of this questionnaire (Blau and Barak 2012) reported good internal consistency: Cronbach's $\alpha=0.80$ for the extroversion-introversion subscale and $\alpha=0.74$ for the emotional stability-neuroticism subscale. The reliability scores found in the current study were similar: extroversion-introversion, $\alpha=0.82$; emotional stability-neuroticism, $\alpha=0.74$.

Perceived learning was measured using a self-report questionnaire (Caspi and Blau 2008, 2011) which assesses three subscales: cognitive, emotional and social aspects of perceived learning. The questionnaire was administered after participants had participated in the lecture. Items in the questionnaire were measured on a 6-point scale ranging from 1 (strongly disagree) to 6 (strongly agree). Mean scores were calculated for each subscale. The cognitive facet of perceived learning was measured through six items (e.g. 'The lesson expanded my knowledge'; Range: 2.17-6.00, Median: 4.67, Mean: 4.61, SD: 0.81, Skewness: -0.51). The emotional facet was assessed through three reversed items, for example, 'The lesson was boring', 'The content of the lesson was difficult' (Range: 2.00-6.00, Median: 5.00, Mean: 4.99, SD: 0.95, Skewness: -1.20 ). The social facet was also measured by three items (e.g. 'I enjoyed the interaction with the instructor during the lecture'; Range: 2.67-6.00, Median: 5.00, Mean: 5.07, SD: 0.68, Skewness: -0.73). A previous study (Caspi and Blau 2011) found the following reliability scores for the questionnaire subscales: cognitive subscale $\alpha$ $=0.74$, emotional and social subscales $\alpha$ 's $=0.90$. In the current study, the following reliability scores were found: cognitive subscale $\alpha=0.89$, emotional subscale $\alpha=0.76$, social subscale: $\alpha=0.77$.

The achievement test was used to assess the knowledge acquired during the lecture on 'The Charisma of Politicians' (see details in the Procedure section). This multiplechoice test was developed especially for the study and its validity was evaluated by three researchers who were experts in the relevant field. The test consisted of 11 multiple-choice questions (with 4 possible answers to each question) which represented 2 levels of knowledge as defined by Bloom et al. (1956): (1) the lowest level of knowledge - 'remembering' (literal subscale) and (2) a higher level of knowledge - 'applying' (inference subscale). The literal subscale was measured by six items (Range: 0.17-1.00, Median: 0.83, Mean: 0.84, SD: 0.18, Skewness: -1.25 ), and the inference subscale was assessed by five items (Range: 0.40-1.00, Median: 1.00, Mean: 0.89, SD: 0.16, Skewness: -1.33). The scores for each of the subscales were calculated as the mean of the responses to the relevant items.

A socio-demographic questionnaire included questions about age, gender and academic status (student or not, and academic discipline).

\section{Procedure}

The study was approved by the Institutional Ethics Committee. The experiment was conducted in the Institutional Lab for Psychology and Education. In the experiment, participants were randomly assigned to gender-balanced classroom-like groups of approximately seven participants. Each group learned in one of three experimental conditions: (1) a traditional face-to-face lesson, which was held in a classroom (faceto-face condition), (2) a two-way video conferencing lesson or (3) a one-way videoconferencing lesson. In the face-to-face condition, participants sat around a table, across from the lecturer. The online conditions (one-way or two-way videoconferencing) were 


\section{Blau et al.}

designed to resemble an online learning environment and both of them were conducted using the Zoom application. Accordingly, in the one-way condition, each participant sat alone in a separate room, in front of a computer, wearing headphones with a microphone and participated in the online lesson, in which only the instructor was seen on video. The setting in the two-way videoconferencing condition was similar, except that a webcam was connected to each participant's computer and both the instructor and the students were seen on video.

After online completion of the socio-demographic and personality traits questionnaires, each group participated in a lesson that was conducted according to one of the three experimental conditions described above (i.e. face-to-face, one-way or two-way videoconferencing). The lesson ( $25 \mathrm{~min})$, entitled 'Charisma of Politicians $=$ Vision + Presentation' was delivered by an expert instructor, experienced in both face-to-face and synchronous teaching and unaware of the research hypotheses. The topic was chosen, among other reasons, because it frames common knowledge of the participants about politics in an unusual way, providing students with a new perspective through which politics can be understood, while enabling them to express their own opinions. In each condition, the lesson contained two similar key pedagogical components: (1) presentation - a frontal lecture without explicit attempts by the instructor to encourage interactions with the students (although students could interrupt the instructor and initiate interactions to comment or ask questions) and (2) activities that were explicitly designed to increase learning-related dialogue: instructor-student interactions, student-instructor communication and interactions between the students themselves (by asking and encouraging questions and promoting discussions between the participants) (Marquart et al. 2016). The two pedagogical components were chosen to enable generalisation of the research findings to both presentations in large introductory courses and to highly interactive teaching in small advanced courses.

All lessons were videotaped, transcribed and then analysed. The teaching-learning interactions were coded by a research assistant unaware of the research hypotheses, into one of the following four categories: instructor's presentation, instructor-student interaction, student-instructor interaction or student-student interaction. For interrater reliability, all transcripts were independently reviewed by a second judge and $25 \%$ of the transcripts were reviewed by a third judge. This was followed by a discussion regarding the attribution of each section in the lesson to a particular teaching-learning style, which was held among the judges until full consensus was reached. All four categories were present in each lesson and since the pedagogy of the lesson was carefully designed before the experiment, as expected, there was no difference between the technological conditions in the time devoted by the instructor to each teaching-learning style. The impact of the aforementioned teaching-learning styles on achievement or perceived learning cannot be separated and thus it is not analysed in this paper.

Immediately following the lesson, participants completed the achievement test and the perceived learning questionnaire. The test and the questionnaire were administrated online, using Google Forms application. SPSS 22 programme was used to analyse the data.

\section{Results}

Since each experimental condition (i.e. face-to-face, one-way and two-way videoconferencing) was conducted in small subgroups, with approximately seven participants in 
each subgroup, the ANOVAs were nested according to the subgroups. This procedure made it possible to control for the potential influence of the dynamics in each of the different subgroups on the dependent variables. Findings indicated no significant differences between the subgroups; thus, for the purpose of examining the research hypotheses, we related to all subgroups as one group representing each experimental condition.

\section{Medium and personality effects on academic achievement}

In order to examine the first hypothesis concerning the effect of medium naturalness and personality traits on academic achievement, two-way ANOVA tests were conducted with the achievement scores for literal and inferential knowledge as the dependent variables and medium naturalness (face-to-face, one-way or two-way videoconferencing) and personality traits (emotional stability-neuroticism or extroversion-introversion) as the independent variables. LSD post-hoc analyses were conducted to examine the differences between the medium naturalness groups.

The effect of medium naturalness and emotional stability-neuroticism on literal knowledge (Table 2). No significant effect was found for medium naturalness, $F(2,73)=1.53, p=0.13$, but the effect size was medium $\left(\eta_{\mathrm{p}}^{2}=0.04\right)$, indicating that students in the face-to-face condition gained more literal knowledge $(M=0.88)$ than students in the one-way videoconferencing condition $(M=0.80)$. Emotional stability-neuroticism had a statistically significant effect with a medium effect size, $F(1,74)=8.07, p=0.01, \mathrm{p} \eta^{2}=0.10$, indicating that emotionally stable students $(M=0.89)$ acquired more literal knowledge than neurotic students $(M=0.78)$. The interaction effect was not significant, $F(2,73)=1.38, p=0.16$, but the effect size was medium $\left(\mathrm{p} \eta^{2}=0.04\right)$, indicating that the advantage of emotionally stable students over neurotic students in the acquisition of literal knowledge was found only in the online experimental conditions, and not in face-to-face classrooms.

The effect of medium naturalness and emotional stability-neuroticism on inferential knowledge (Table 2). No significant effect was found for medium naturalness on

Table 2. Means and standard deviations (M(SD)) on measures of learning achievement according to medium naturalness and emotional stability-neuroticism

\begin{tabular}{lllll}
\hline & & & \multicolumn{2}{c}{ Learning achievement } \\
\cline { 4 - 5 } Medium naturalness & $\begin{array}{c}\text { Personality: emotional } \\
\text { stability-neuroticism }\end{array}$ & $N$ & $\begin{array}{c}\text { Literal } \\
\text { knowledge }\end{array}$ & $\begin{array}{c}\text { Inferential } \\
\text { knowledge }\end{array}$ \\
\hline Face-to-face & Emotionally stable & 13 & $0.88(0.14)$ & $0.91(0.10)$ \\
& Neurotic & 11 & $0.86(0.18)$ & $0.89(0.19)$ \\
One-way & Total & 24 & $0.88(0.16)$ & $0.90(0.14)$ \\
videoconferencing & Emotionally stable & 14 & $0.88(0.14)$ & $0.97(0.07)$ \\
& Neurotic & 12 & $0.71(0.19)$ & $0.87(0.13)$ \\
Two-way & Total & 26 & $0.80(0.18)$ & $0.92(0.11)$ \\
videoconferencing & Emotionally stable & 9 & $0.93(0.09)$ & $0.96(0.13)$ \\
& Neurotic & 17 & $0.78(0.21)$ & $0.79(0.19)$ \\
Total & Total & 26 & $0.83(0.19)$ & $0.85(0.19)$ \\
& Emotionally stable & 36 & $0.89(0.13)$ & $0.94(0.10)$ \\
& Neurotic & 40 & $0.78(0.20)$ & $0.84(0.18)$ \\
& Total & 76 & $0.84(0.18)$ & $0.89(0.15)$ \\
\hline
\end{tabular}




\section{Blau et al.}

inferential knowledge, $F(2,73)=0.65, p=0.52, \mathrm{p} \eta^{2}=0.02$. Emotional stabilityneuroticism had a statistically significant effect with a medium effect size, $F(1,74)=$ 8.05, $p=0.01,{ }_{\mathrm{p}} \eta^{2}=0.10$, indicating that emotionally stable students $(M=0.94)$ gained more inferential knowledge than neurotic students $(M=0.84)$. The interaction effect was not significant, $F(2,73)=1.61, p=0.21$, but the effect size was medium $\left(\mathrm{p} \eta^{2}=0.04\right)$, indicating that the advantage of emotionally stable students over neurotic students in the acquisition of inferential knowledge was only found in the online experimental conditions, and not among those who were in the face-to-face learning group.

The effect of medium naturalness and extroversion-introversion on literal knowledge (Table 3). No significant effect was found for medium naturalness, $F(2,73)=1.45, p=0.18$, but the effect size was medium $\left({ }_{p} \eta^{2}=0.04\right)$, indicating that students in the face-to-face condition gained more literal knowledge $(M=0.88)$ than students in the one-way videoconferencing condition $(M=0.80)$. Extroversion-introversion was not found to have a significant effect on literal knowledge, $F(1,74)=0.67, p=0.42,{ }_{p} \eta^{2}=0.01$. The interaction effect was not significant $F(2,73)=1.36, p=0.26$, but the effect size was medium $\left({ }_{\mathrm{p}} \eta^{2}=0.04\right)$, indicating that in the face-to-face learning condition, introverts gained more literal knowledge than extroverts, whereas in the online learning conditions, extroverts scored higher than introverts.

The effect of medium naturalness and extroversion-introversion on inferential knowledge (Table 3). No significant effect was found for medium naturalness, $F(2,73)=1.23, p=0.20$, but the effect size was medium $\left({ }_{\mathrm{p}} \eta^{2}=0.04\right)$, indicating that students in the one-way videoconferencing condition gained more inferential knowledge $(M=0.92)$ than students in the two-way videoconferencing condition $(M=0.85)$. No significant effect was found for extroversion-introversion, $F(1,74)=$ 2.70, $p=0.11$ but the effect size was medium $\left(\eta^{2}=0.04\right)$, indicating that introverts gained less inferential knowledge $(M=0.85)$ than extroverts $(M=0.92)$. The interaction effect was not significant, $F(2,73)=0.28, p=0.76,{ }_{\mathrm{p}} \eta^{2}=0.01$.

Table 3. Means and standard deviations $(\mathrm{M}(\mathrm{SD}))$ on measures of learning achievement according to medium naturalness and extroversion-introversion

\begin{tabular}{lllll}
\hline & & & \multicolumn{2}{c}{ Learning achievement } \\
\cline { 3 - 5 } Medium naturalness & $\begin{array}{c}\text { Personality: } \\
\text { extroversion-introversion }\end{array}$ & $N$ & $\begin{array}{c}\text { Literal } \\
\text { knowledge }\end{array}$ & $\begin{array}{c}\text { Inferential } \\
\text { knowledge }\end{array}$ \\
\hline Face-to-face & Introverts & 11 & $0.91(0.14)$ & $0.85(0.18)$ \\
& Extroverts & 13 & $0.85(0.17)$ & $0.94(0.10)$ \\
One-way & Total & 24 & $0.88(0.16)$ & $0.90(0.14)$ \\
videoconferencing & Introverts & 10 & $0.75(0.18)$ & $0.88(0.14)$ \\
& Extroverts & 16 & $0.83(0.18)$ & $0.95(0.09)$ \\
Two-way & Total & 26 & $0.80(0.18)$ & $0.92(0.11)$ \\
videoconferencing & Introverts & 16 & $0.80(0.22)$ & $0.84(0.20)$ \\
& Extroverts & 10 & $0.88(0.11)$ & $0.86(0.19)$ \\
Total & Total & 26 & $0.83(0.19)$ & $0.85(0.19)$ \\
& Introverts & 37 & $0.82(0.19)$ & $0.85(0.17)$ \\
& Extroverts & 39 & $0.85(0.16)$ & $0.92(0.13)$ \\
& Total & 76 & $0.84(0.18)$ & $0.89(0.15)$ \\
\hline
\end{tabular}




\section{The effect of medium and personality on perceived learning}

In order to examine the second hypothesis, concerning the effect of medium naturalness and personality traits on perceived learning, two-way ANOVA tests were conducted with the subscales of perceived learning (cognitive, emotional and social aspects) as dependent variables and medium naturalness and personality traits as the independent variables. LSD post-hoc analyses were conducted to examine the differences between the groups.

The effect of medium naturalness and emotional stability-neuroticism on the cognitive aspect of perceived learning (Table 4). No significant effect was found for medium naturalness, $F(2,73)=1.64, p=0.15$, but the effect size was medium $\left({ }_{\mathrm{p}} \eta^{2}\right.$ $=0.05$ ), indicating that students in the one-way videoconferencing condition felt they gained more knowledge $(M=4.79)$ than students in the face-to-face condition $(M=4.42)$. Emotional stability-neuroticism had a statistically significant effect with a medium effect size, $F(1,74)=4.72, p=0.03, \mathrm{p} \eta^{2}=0.06$, indicating higher scores on the cognitive aspect of perceived learning among emotionally stable students $(M=$ $4.81)$ than among neurotic students $(M=4.43)$. The interaction effect was not significant, $F(2,73)=1.34, p=0.27$, but the effect size was medium $\left(\eta^{2}=0.04\right)$, indicating that in the experimental conditions, the advantage of emotionally stable students over neurotic students in the cognitive aspect of perceived learning was the strongest in the face-to-face condition.

The effect of medium naturalness and emotional stability-neuroticism on the emotional aspect of perceived learning (Table 4). A marginally significant effect with a medium effect size was found for medium naturalness, $F(2,73)=2.61, p=0.07$, $\mathrm{p} \eta^{2}=0.08$, indicating more enjoyment from learning in the face-to-face condition $(M=5.38$ ), compared to the online conditions (one-way videoconferencing: $M=$ 4.85, two-way videoconferencing: $M=4.77$ ). Emotional stability-neuroticism had a statistically significant effect, with a large effect size, $F(1,74)=1.68, p=0.02,{ }_{p} \eta^{2}=$ 0.20 , indicating more enjoyment from learning among emotionally stable students $(M=5.15)$ than among neurotic students $(M=4.84)$. The interaction effect was significant and the effect size was large, $F(2,73)=1.57, p=0.04,{ }_{\mathrm{p}} \eta^{2}=0.22$, indicating

Table 4. Means and standard deviations $(\mathrm{M}(\mathrm{SD}))$ on measures of perceived learning according to medium naturalness and emotional stability-neuroticism

\begin{tabular}{llllcc}
\hline & & & \multicolumn{3}{c}{ Perceived learning } \\
\cline { 5 - 6 } Medium & Personality: emotional & & Cognitive & Emotional & Social \\
naturalness & stability-neuroticism & $N$ & aspect & aspect & aspect \\
\hline Face-to-face & Emotionally stable & 13 & $4.79(0.70)$ & $5.73(0.33)$ & $5.36(0.44)$ \\
& Neurotic & 11 & $3.97(0.69)$ & $4.95(1.11)$ & $4.88(0.65)$ \\
One-way & Total & 24 & $4.42(0.80)$ & $5.38(0.86)$ & $5.14(0.59)$ \\
videoconferencing & Emotionally stable & 14 & $4.90(0.44)$ & $4.79(0.70)$ & $4.88(0.50)$ \\
& Neurotic & 12 & $4.67(0.92)$ & $4.92(1.16)$ & $4.92(1.03)$ \\
Two-way & Total & 26 & $4.79(0.70)$ & $4.85(0.92)$ & $4.90(0.77)$ \\
videoconferencing & Emotionally stable & 9 & $4.69(0.96)$ & $4.89(0.93)$ & $5.33(0.71)$ \\
& Neurotic & 17 & $4.55(0.91)$ & $4.71(1.02)$ & $5.10(0.64)$ \\
Total & Total & 26 & $4.60(0.91)$ & $4.77(0.97)$ & $5.18(0.66)$ \\
& Emotionally stable & 36 & $4.81(0.68)$ & $5.15(0.78)$ & $5.17(0.57)$ \\
& Neurotic & 40 & $4.43(0.89)$ & $4.84(1.06)$ & $4.98(0.77)$ \\
& Total & 76 & $4.61(0.81)$ & $4.99(0.95)$ & $5.07(0.68)$ \\
\hline
\end{tabular}




\section{Blau et al.}

that in the face-to-face and two-way videoconferencing conditions, emotionally stable students enjoyed learning to a greater extent than neurotic students, whereas in the one-way videoconferencing condition, neurotic students enjoyed learning to a greater extent than emotionally stable students. The difference between emotionally stable and neurotic students was largest in the face-to-face condition.

The effect of medium naturalness and emotional stability-neuroticism on the social aspect of perceived learning (Table 4). No significant effect was found for medium naturalness, $F(2,73)=1.43, p=0.15$, but the effect size was medium $\left(\eta^{2}=0.04\right)$, indicating that students in the two-way videoconferencing condition $(M=5.18)$ enjoyed the social interactions to a greater extent than students in the one-way videoconferencing condition $(M=4.90)$. Emotional stability-neuroticism did not have a significant effect, $F(1,74)=2.05, p=0.16$, but the effect size was medium $\left(\eta_{p}^{2}=0.04\right)$, indicating that emotionally stable students enjoyed the social interactions $(M=5.17)$ more than neurotic students $(M=4.98)$. The interaction effect was not significant, $F(2,73)=1.90$, $p=0.19$, but the effect size was medium $\left({ }_{\mathrm{p}} \eta^{2}=0.04\right)$, indicating that in the face-to-face and two-way videoconferencing conditions, emotionally stable students enjoyed the social interactions to a greater extent than neurotic students, whereas in the oneway videoconferencing condition, neurotic students enjoyed the social interactions to a greater extent than emotionally stable students. The difference between emotionally stable and neurotic students was largest in the face-to-face condition.

The effect of medium naturalness and extroversion-introversion on the cognitive aspect of perceived learning (Table 5). No significant effect was found for medium naturalness, $F(2,73)=1.18, p=0.21$, but the effect size was medium $\left({ }_{p} \eta^{2}=0.03\right)$, indicating that students in the one-way videoconferencing condition felt they had learned more $(M=4.79)$ than students in the face-to-face condition $(M=4.42)$. No significant effect was found for extroversion-introversion, $F(1,74)=2.42, p=0.12$, but the effect size was medium $\left({ }_{\mathrm{p}} \eta^{2}=0.04\right)$, indicating that extroverts felt they had learned more $(M=4.76)$ than introverts $(M=4.45)$. The interaction effect was not significant, $F(2,73)=0.02, p=0.99, \mathrm{p}^{2}=0.00$.

Table 5. Means and standard deviations $(\mathrm{M}(\mathrm{SD}))$ on measures of perceived learning according to medium naturalness and extroversion-introversion

\begin{tabular}{llllll}
\hline & & & \multicolumn{3}{c}{ Perceived learning } \\
\cline { 4 - 6 } $\begin{array}{l}\text { Medium } \\
\text { naturalness }\end{array}$ & $\begin{array}{c}\text { Personality: } \\
\text { extroversion-introversion }\end{array}$ & $N$ & $\begin{array}{c}\text { Cognitive } \\
\text { aspect }\end{array}$ & $\begin{array}{c}\text { Emotional } \\
\text { aspect }\end{array}$ & $\begin{array}{c}\text { Social } \\
\text { aspect }\end{array}$ \\
\hline Face-to-face & Introverts & 11 & $4.24(0.95)$ & $5.36(0.81)$ & $4.91(0.70)$ \\
& Extroverts & 13 & $4.56(0.65)$ & $5.38(0.94)$ & $5.33(0.41)$ \\
& Total & 24 & $4.42(0.80)$ & $5.38(0.86)$ & $5.14(0.59)$ \\
One-way & Introverts & 10 & $4.60(0.83)$ & $4.85(1.25)$ & $4.97(0.96)$ \\
videoconferencing & Extroverts & 16 & $4.92(0.60)$ & $4.84(0.70)$ & $4.85(0.66)$ \\
& Total & 26 & $4.79(0.70)$ & $4.85(0.92)$ & $4.90(0.77)$ \\
Two-way & Introverts & 16 & $4.50(0.85)$ & $4.78(0.95)$ & $5.06(0.69)$ \\
videoconferencing & Extroverts & 10 & $4.75(1.04)$ & $4.75(1.06)$ & $5.37(0.60)$ \\
& Total & 26 & $4.60(0.91)$ & $4.77(0.97)$ & $5.18(0.66)$ \\
Total & Introverts & 37 & $4.45(0.86)$ & $4.97(1.01)$ & $4.99(0.76)$ \\
& Extroverts & 39 & $4.76(0.75)$ & $5.00(0.90)$ & $5.15(0.61)$ \\
& Total & 76 & $4.61(0.81)$ & $4.99(0.95)$ & $5.07(0.68)$ \\
\hline
\end{tabular}


The effect of medium naturalness and extroversion-introversion on the emotional aspect of perceived learning (Table 5). A marginally significant effect with a medium effect size was found for medium naturalness $F(2,73)=2.96, p=0.06$, ${ }_{\mathrm{p}} \eta^{2}=0.08$, indicating greater enjoyment from learning among students in the face-to-face learning conditions $(M=5.38)$ compared to the online conditions (one-way videoconferencing: $M=4.85$; two-way videoconferencing: $M=4.77$ ). No significant effects were found for the extroversion-introversion factor, $F(1,74)=0.00, p=0.98,{ }_{p} \eta^{2}=0.00$, or the interaction between extroversion-introversion and medium naturalness, $F(2,73)=$ $0.01, p=1.00,{ }_{\mathrm{p}} \eta^{2}=0.00$.

The effect of medium naturalness and extroversion-introversion on the social aspect of perceived learning (Table 5). No significant effect was found for medium naturalness, $F(2,73)=1.30, p=0.18$, but the effect size was medium $\left(\eta^{2}=0.04\right)$, indicating that students in the two-way videoconferencing condition enjoyed the social interactions $(M=5.18)$ to a greater extent than students in the one-way videoconferencing condition $(M=4.90)$. No significant effect was found for extroversion-introversion, $F(1,74)=1.68, p=0.20, \mathrm{p} \eta^{2}=0.02$. The interaction effect was not significant, $F(2,73)=1.66, p=0.15$, but the effect size was medium $\left({ }_{\mathrm{p}} \eta^{2}=0.03\right)$, indicating that in the face-to-face and two-way videoconferencing conditions, extroverts enjoyed the social interactions to a greater extent than introverts, whereas in the one-way videoconferencing condition, introverts enjoyed the social interactions to a greater extent than extroverts. The difference between extroverts and introverts was the largest in the face-to-face condition.

\section{Discussion}

This experimental study focused on the Medium Naturalness Theory (Kock 2005), comparing the effect of learning with different levels of medium naturalness (i.e. face-to-face and synchronous e-learning through one-way and two-way videoconferencing conditions) on learning achievement and perceived learning. This effect was examined in interaction with students' personality traits which have been reported in the literature as relevant to e-communication and e-learning.

\section{The effect of media and personality on learning achievement}

This study measured the achievement of literal and inferential knowledge separately, making it possible to distinguish between learning competencies that involve remembering facts and making inferences from acquired knowledge. In accordance with our first hypothesis, compared to the one-way videoconferencing condition, acquisition of literal knowledge was found to be greater in the face-to-face condition. It is important to note that the participants were aware of the fact that they were going to take a comprehension test after the lecture. However, since the participants knew that during the test they would not be allowed to use the notes that some of them took during the lecture, they did their best to memorise the lecture's content. In accordance with the MNT (Kock 2005), we suggest that the low level of medium naturalness in the oneway videoconferencing condition imposed a high cognitive load on the learners (Reychav, Warkentin and McHaney 2015; Tapsis and Tsolakidis 2015), which affected their scores on the achievement test. However, contrary to our first hypothesis and to the predictions of the MNT, participants in the one-way videoconferencing 


\section{Blau et al.}

condition gained more inferential knowledge compared to those in the two-way videoconferencing condition. Similar findings have been reported in the literature (e.g. Redpath 2012). This result indicates that medium naturalness has a differential effect on achievement for different types of knowledge which present different magnitudes of cognitive load. We argue that the explanation for these findings lies in the differences between low-level literal knowledge and the higher-level and more cognitively challenging inferential knowledge (Bloom et al. 1956; Anderson et al. 2001). These findings reflect the interplay/trade-off that exists in e-learning, between medium naturalness and the cognitive challenges posed to the learners by the level of the content complexity (Clabaugh, Forbes, and Clabaugh 1995). Note that our findings do not refer to the complexity of messages conveyed by the instructor, in terms of the Medium Richness Theory, but rather to the complexity of knowledge that the student has acquired. In other words, a high level of medium naturalness might hinder the understanding of a very complicated type of knowledge, such as inferential knowledge, whereas it might foster the achievement for simple types of knowledge, such as literal knowledge. Equivalent findings, from

a different field of research (reading comprehension), were reported by Ben-Yehudah and Eshet-Alkalai (2014), who found that the use of highlighting when reading the text improved understanding only for the easy-to-learn literal knowledge and not for the more cognitively challenging inferential knowledge. More research is required in order to shed light on the pros and cons of medium naturalness in relation to academic achievement for different types of knowledge.

In accordance with our first hypothesis and with previous studies on emotional stability-neuroticism in face-to-face learning environments (Chamorro-Premuzic and Furnham 2003; Furnham, Nuygards and Chamorro-Premuzic 2013), examination of the effect of this personality trait on learning achievement indicated that in general, the emotionally stable participants gained more knowledge than the neurotic participants. The interaction effect between emotional stability-neuroticism and medium naturalness indicated that the advantage of emotionally stable students over neurotic students was only found in the online learning conditions, and not in the face-to-face ones. This implies that indeed, lower levels of medium naturalness are associated with less effective learning, but with regard to the emotional stability trait, this is true only for neurotic students, supporting the claim that in online environments, 'the rich get richer' (Kraut et al. 2002). Thus, this finding does not support the 'promise' of the more recent literature concerning the potential of online environments in empowering learners who have difficulty expressing themselves through conventional communication channels (Amichai-Hamburger 2005, 2007). One possible explanation for this finding might be that the Zoom videoconferencing application, which was used in this study for the online experimental conditions, was new to all the participants and may have led to high anxiety among neurotic students, exaggerating differences in their learning abilities compared to emotionally stable students. This potential disadvantage that neurotic students have should be taken into account during the integration of new technologies in learning in general, and in online learning in particular.

In contrast with the first study hypothesis, extroverts were not found to have a consistent advantage in acquiring knowledge in comparison with introverts. Whereas in the face-to-face condition, introverts gained more literal knowledge than extroverts, in the two online conditions, introverts gained less literal knowledge than extroverts. 
This finding may imply that in the face-to-face learning condition, extroverts directed more resources to social activities (Blau and Barak 2009a; Voorn and Kommers 2013), resulting in the acquisition of less literal knowledge, while introverts were more focused on learning. In contrast, in the online learning conditions, which are associated with less social distractions (Kock, Verville, and Garza 2007), the extroverts could exercise their learning advantages. Contrary to our hypotheses, no significant effects were found for the extroversion-introversion trait or its interaction with medium naturalness on inferential knowledge. In summary, as in previous studies (Blau and Barak 2011; Chamorro-Premuzic and Furnham 2003), this study did not find clear-cut evidence for an association between extroversion and academic achievement. However, the differences between literal and inferential knowledge emphasise the importance of developing tests that examine the two types of learning achievement separately for research purposes, while addressing both types of knowledge in academic assessments.

\section{The effect of media and personality traits on perceived learning}

This study examined three aspects of perceived learning: cognitive, emotional and social. Following Sebastianelli, Swif, and Tamimi (2015), who found that the type of content being studied may affect different aspects of perceived learning in online environments, in the current study all students were exposed to the same content. This made it possible to neutralise the influence of the content and to examine additional factors which may affect perceived learning.

In contrast with our second research hypothesis, regarding the influence of medium naturalness and participants' personality on different aspects of perceived learning, findings indicated that students in the one-way videoconferencing condition felt that they understood the content and learned better (cognitive aspect) than students in the face-to-face condition. The perceived overconfidence of digital learners in their achievements is well-known from other fields of research, such as in reading studies, in which digital readers are often overconfident in their performance with digital reading compared to print reading (Ackerman and Goldsmith 2011; Eshet-Alkalai and Geri 2007; Lauterman and Ackerman 2014; Sidi, Ophir, and Ackerman 2016; Sidi et al. 2017). However, in accordance with the second hypothesis, students from the face-to-face condition perceived learning to be easier and more interesting (emotional aspect) than students from the online learning environments (one-way and two-way videoconferencing conditions). This might be explained by the frustration, high cognitive load and attention-splitting problems which are reported in many studies to be involved with online learning (e.g. Clark and Mayer 2016; Paas, Renkl and Sweller 2003). Students in the more natural learning conditions (i.e. faceto-face and two-way videoconferencing) reported greater enjoyment from the social interactions with the instructor and peers than the students in the one-way videoconferencing, which conveys less social communication cues. Thus, it seems that communication media that are low in naturalness and social communication cues, such as one-way videoconferencing, impair the perceived emotional and social aspects of learning, but enhance the cognitive aspect. This trade-off is in accordance with the results of a previous experimental study (Blau and Caspi 2010), which compared a face-to-face classroom with audioconferencing - a communication channel with fewer social communication cues. The findings revealed that learning via 


\section{Blau et al.}

audioconferencing led to perceptions of greater understanding (cognitive aspect), but to more negative perceptions regarding learning interactions with teacher and peers (social aspect), as well as perceptions of learning as more difficult and boring (emotional aspect).

In accordance with our second hypothesis and with findings from the literature (e.g. Chamorro-Premuzic and Furnham 2003; Furnham, Nuygards and ChamorroPremuzic 2013), examination of the influence of emotional stability-neuroticism on perceived learning indicates that emotionally stable students perceive learning more positively than neurotic students. However, the analysis of each aspect of perceived learning separately reveals different patterns for the cognitive versus the socialemotional aspects in the different learning conditions. While in the face-to-face condition, emotionally stable students scored higher than neurotic students on the cognitive aspect of perceived learning, this difference was smaller or non-existent in the online learning conditions. Moreover, in relation to the social and emotional aspects of perceived learning, emotionally stable participants scored higher than neurotic students in the more natural learning conditions (i.e. face-to-face and two-way videoconferencing), whereas neurotic students felt more comfortable, both socially and emotionally than emotionally stable students in the less natural one-way videoconferencing condition. Thus, similar to previous results (McKenna et al. 2007) and in accordance with the concept of 'the poor gets richer' (Amichai-Hamburger 2005, 2007), our findings demonstrate the potential of online learning interactions to benefit disadvantaged populations.

Regarding the impact of the extroversion-introversion trait, in accordance with our second hypothesis, extroverts scored higher on perceived learning, compared to introverts. Nonetheless, an examination of the three aspects of perceived learning (i.e. cognitive, social and emotional) in the different learning conditions (i.e. faceto-face, one-way and two-way videoconferencing) indicated that extroverts scored higher on the cognitive aspect of perceived learning in all of the learning conditions. No significant differences were found between extroverts and introverts in relation to the emotional aspect of perceived learning. As expected, extroverts were found to have higher scores than introverts on the social aspect of perceived learning in the most natural learning environments (i.e. face-to-face and two-way videoconferencing), whereas in the one-way videoconferencing condition, introverts had higher scores than extroverts. This finding illustrates the better suitability of one-way videoconferencing for introverted students, in accordance with 'the poor get richer approach' (AmichaiHamburger 2005, 2007; Amichai-Hamburger and Hayat 2013) and with previous findings (Blau and Barak 2012), indicating that introverts are more comfortable in less natural online learning environments. Previous studies have also found that introverts may even adopt extroverted behaviour in asynchronous (Amichai-Hamburger 2007) and synchronous online environments (Blau and Barak 2012). Our findings highlight the importance of tailoring online learning and training, as well as synchronous work environments, to the participant's personality, beyond the potential benefits of the technological conditions per se. For example, in a synchronous session, it is recommended to let the learners/workers/trainees decide whether or not to use the webcam, rather than oblige all the participants to use a two-way video communication. Similarly, it is recommended to allow participants to choose between face-to-face and online learning, collaboration or meetings, based on their personal preference, guided by personality traits. 


\section{Conclusions, limitations and future research directions}

The comparison between learning conditions, that have different levels of naturalness, in academic achievement and perceived learning, did not reveal an absolute superiority of any of the modes of learning (i.e. face-to-face, one-way and two-way videoconferencing). However, in general, our findings point to the advantage of learning conditions which have a high level of medium naturalness (i.e. face-to-face learning). Similar to previous studies (Blau and Caspi 2008, 2010; Kock 2005; Kock, Verville, and Garza 2007), the findings of this study indicate that learning with advanced communication media, which enable simultaneous communication through different channels, impose a high cognitive load on learners and may impair the quality of learning and the learning experience.

Nonetheless, as indicated by the interaction effects between personality traits and medium naturalness on learning achievement and perceived learning, this is not the case for everyone. Our findings highlight the importance of tailoring teaching methods and learning conditions, as well as synchronous professional training and work environments to participants' characteristics and needs. Since this study was conducted under synchronous conditions, our findings cannot be generalised to asynchronous e-learning environments. However, they are generalisable to synchronous professional training through webinars, as well as for synchronous communication and collaboration of virtual teams in the workplace. The findings of this study emphasise the pivotal role that students' or workers' personality traits play in their ability to adjust to, succeed in and engage in learning or work interactions in different environments.

The findings included a number of results which were not statistically significant but had a medium effect size. It is plausible that the reason for this is the modest size of the research sample and that increasing the sample size would lead to more statistically significant findings. Replicating this experiment with larger groups of students in each condition would also enable an examination of additional variables which have been associated with online behaviour, including age and gender (Amichai-Hamburger and Ben-Artzi 2003). In addition, the lecture which was the focus of the experiment was relatively short, influencing the amount of information which was taught and tested immediately after the lesson. A longer lecture might have made it possible to teach and discuss more information and to test the knowledge which was acquired on additional levels of knowledge according to Bloom et al. (1956). In addition to the post-test, previous research has shown (e.g. Barzilai and Blau 2014) that delayed testing and measurement of cognitive perceived learning can provide additional insights into whether the content was properly elaborated and integrated into long-term memory. Furthermore, it is plausible that the group size, which was limited to seven participants for technical reasons, influenced the group dynamic which affects the emotional and the social aspects of perceived learning. Lessons with more participants in each class would make the experimental condition more similar to the reality of academic learning, in which classes include significantly more than seven students and are 1-2 h long. Finally, the experiment was designed in accordance with the Western-style educational setting and might be only partially generalisable to cultures with different learning environments. In accordance with these limitations, future studies should be conducted in a variety of educational settings, using larger samples with larger groups of students in each class, and longer lesson times. 


\section{Blau et al.}

\section{Acknowledgement}

This study was supported by the research grant from MEITAL - IUCC: Israeli Inter-University Center for E-Learning.

\section{Conflict of interest and funding}

The authors declare that they have no conflicts of interests.

\section{References}

Ackerman, R. \& Goldsmith, M. (2011) 'Metacognitive regulation of text learning: on screen versus on paper', Journal of Experimental Psychology: Applied, vol. 17, no. 1, pp. 18-32.

Amichai-Hamburger, Y. (2005) 'Personality and the Internet', in The Social Net: Human Behavior in Cyberspace, ed. Y. Amichai-Hamburger, Oxford University Press, New York, pp. 27-55.

Amichai-Hamburger, Y. (2007) 'Personality, individual differences and Internet use', in Oxford Handbook of Internet Psychology, eds A. Joinson et al., Oxford University Press, Oxford, UK, pp. 187-204.

Amichai-Hamburger, Y. \& Ben-Artzi, E. (2003) 'Loneliness and Internet use', Computers in Human Behavior, vol. 19, no. 1, pp. 71-80.

Amichai-Hamburger, Y. \& Hayat, Z. (2013) 'Internet and personality', in The Social Net: Understanding Our Online Behavior, ed. Y. Amichai-Hamburger, Oxford University Press, New York, NY, US, 2nd ed., Chapter 1, pp. 1-20, http://dx.doi.org/10.1093/ acprof:oso/9780199639540.003.0001

Anderson, L. W., Krathwohl, D. R., Airasian, P., Cruikshank, K., Mayer, R. \& Pintrich, P., et al. (2001) A taxonomy for learning, teaching and assessing: A revision of Bloom's taxonomy, Longman Publishing, New York.

Akyol, Z. \& Garrison, D. R. (2014) 'The development of a community of inquiry over time in an online course: Understanding the progression and integration of social, cognitive and teaching presence', Journal of Asynchronous Learning Networks, vol. 12, no. 3-4, pp. 3-22.

Baehr, C. (2012) 'Incorporating user appropriation, media richness, and collaborative knowledge sharing into blended e-learning training tutorial', IEEE Transactions on Professional Communication, vol. 55, no. 2, pp. 175-184.

Barak, A. \& Suler, J. (2008) 'Reflections on the psychology and social science of cyberspace', in Psychological Aspects of Cyberspace: Theory, Research, Applications, ed A. Barak, Cambridge University Press, Cambridge, UK, pp. 1-12.

Barzilai, S. \& Blau, I. (2014) 'Scaffolding game-based learning: Impact on learning achievements, perceived learning, and game experiences', Computer \& Education, vol. 70, no. 0, pp. 65-79.

Ben-Yehudah, G. \& Eshet-Alkalai, Y. (2014) 'The influence of text annotation tools on print and digital reading comprehension', in Learning in the technological era, eds. Y. Eshet-Alkalai, A. Caspi, N. Geri, Y. Kalman, V. Silber-Varod, \& Y. Yair, The Open University of Israel, Ra'anana, Israel. [in Hebrew], pp. 28-35.

Blau, I. \& Barak, A. (2009a) 'Synchronous online discussions: Participation in a group audio conferencing and textual chat as affected by communicator's personality characteristics and discussion topics', in Proceedings of the International Conference on Computer Supported Education - CSEDU'09, Lisbon, Portugal, pp. 19-24.

Blau, I. \& Barak, A. (2009b) 'Talking about, talking online: The effect of personality characteristics, medium type and discussion topic on people's willingness to participate in synchronous online discussion', in Learning in the technological era, eds. Y. Eshet-Alkalai, A. Caspi, S. Eden, N. Geri, \& Y. Yair, The Open University of Israel, Ra'anana, Israel. [in Hebrew], pp. 14-24.

Blau, I. \& Barak, A. (2011) 'Optimization of e-learning: The contribution of personality traits', in Integration of informational technologies into Israeli education systems, eds. D. Hen \& G. Kurtz, Center for Academic Studies, Or Yehuda. [in Hebrew], pp. 61-84. 
Blau, I. \& Barak, A. (2012) 'How do personality, synchronous media, and discussion topic affect participation?', Educational Technology \& Society, vol. 15, no. 2, pp. 12-24.

Blau, I. \& Caspi, A. (2008) 'Do media richness and visual anonymity influence learning? A comparative study using Skype ${ }^{\mathrm{TM}}$, in Learning in the Technological Era, eds. Y. Eshet, A. Caspi \& N. Geri, The Open University of Israel, Ra'anana, Israel, pp. 18-25.

Blau, I. \& Caspi, A. (2010) 'Studying invisibly: Media naturalness and learning', in Evolutionary psychology and information systems research: A new approach to studying the effects of modern technologies on human behavior, ed. N. Kock, Springer, New-York, pp. 193-216.

Bloom, B.S., et al., (1956) Taxonomy of Educational Objectives: The Classification of Educational Goals. Handbook 1: Cognitive Domain, David McKay, New York.

Canto, S., Jauregi, K. \& van den Bergh, H. (2013) 'Integrating cross-cultural interaction through video-communication and virtual worlds in foreign language teaching programs: Is there an added value?', ReCALL, vol. 25, no. 01, pp. 105-121.

Caspi, A. \& Blau, I. (2008) 'Social presence in online discussion groups: Testing three conceptions and their relations to perceived learning', Social Psychology of Education, vol. 11, pp. 323-346.

Caspi, A. \& Blau, I. (2011) 'Collaboration and psychological ownership: How does the tension between the two influence perceived learning?', Social Psychology of Education: An International Journal, vol. 14, pp. 283-298.

Caspi, A. \& Gorsky, P. (2005) 'Instructional media choice: factors affecting the preferences of distance education coordinators', Journal of Educational Multimedia and Hypermedia, vol. 14, no. 2, pp. 169-198.

Chamorro-Premuzic, T. \& Furnham, A. (2003) 'Personality predicts academic performance: evidence from two longitudinal university samples', Journal of Research in Personality, vol. 37, no. 4, pp. 319-338.

Chang, I. \& Chang, W. (2012) 'Effects of e-learning on learning performance - A case study on students in tourism department in Taiwan', Pakistan Journal of Statistics, vol. 28, no. 5, pp. 633-644.

Clabaugh, M. G., Forbes, J. L. \& Clabaugh, J. P. (1995) 'Bloom's cognitive domain theory: a basis for developing higher levels of critical thinking skills in reconstructing a professional selling course', Journal of Marketing Education, vol. 17, no. 3, pp. 25-34.

Clark, R. C. \& Mayer, R. E. (2016) E-Learning and the Science of Instruction: Proven Guidelines for Consumers and Designers of Multimedia Learning, John Wiley \& Sons, Hoboken, New Jersey, US.

Costa, P. T., Jr. \& McCrae, R. R. (1992) Revised NEO Personality Inventory (NEO PI-R) and NEO Five Factor Inventory (NEO FFI) Professional Manual, Psychological Assessment Resources, Odessa, FL.

Daft, R. L. \& Lengel, R. H. (1984) 'Information richness: a new approach to managerial behavior and organization design', in Research in Organizational Behavior, vol. 6, ed B. M. Staw \& L. L. Cummings, JAI, Greenwich, CT, pp. 191-233.

Daft, R. L., Lengel, R. H. \& Treviño, L. K. (1987) 'Message equivocality, media selection, and manager performance: implications for information systems', MIS Quarterly, vol. 11, no. 3, pp. 355-368.

Eshet-Alkalai, Y. \& Geri, N. (2007) 'Does the medium affect the message? The influence of text representation format on critical thinking', Human Systems Management, vol. 26, no. 4, pp. 269-279.

Eysenck, H. J. \& Eysenck, S. E. G. (1975) Manual: Eysenck Personality Inventory, Educational and Industrial Testing Service, San Diego, CA.

Finkelstein, J. E. (2009) Learning in Real Time: Synchronous Teaching and Learning online, Jossey-Bass, A Wiley Imprint, San-Francisco, CA, US.

Furnham, A., Nuygards, S. \& Chamorro-Premuzic, T. (2013) 'Personality, assessment methods and academic performance', Instructional Science, vol. 41, no. 5, pp. 975-987.

Hattie, J. (2009) Visible learning: A synthesis of over 800 meta-analyses relating to achievement, Routledge, New-York, US.

Isaacson, K. (2013) 'An investigation into the affordances of google hangouts for possible use in synchronous online learning environments', in Proceedings of EdMedia: World Conference on Educational Media and Technology 2013, eds J. Herrington, A. Couros \& V. Irvine, Association for the Advancement of Computing in Education (AACE), Waynesville, NC, USA, pp. 2461-2465. 


\section{Blau et al.}

Johnson, G. M. \& Cooke, A. (2015) 'An ecological model of student interaction in online learning environments', in Handbook of Research on Strategic Management of Interaction, Presence, and Participation in Online Courses, IGI Global, Hershey, PA, USA, pp. 1-28.

Keller, S. L. (2013) 'Computer-mediated communication and success in educational collaboration', American Communication Journal, vol. 15, no. 3, pp. 40-58.

Klitmøller, A., Schneider, S. C. \& Jonsen, K. (2015) 'Speaking of global virtual teams: language differences, social categorization and media choice', Personnel Review, vol. 44, no. 2, pp. 270-285.

Kock, N. (2004) 'The psychobiological model: towards a new theory of computer-mediated communication based on Darwinian evolution', Organization Science, vol. 15, no. 3, pp. $327-348$.

Kock, N. (2005) 'Media richness or media naturalness? The evolution of our biological communication apparatus and its influence on our behavior toward e-communication tools', IEEE Transactions on Professional Communication, vol. 48, no. 2, pp. 117-130.

Kock, N. \& Garza, V. (2011) 'Media naturalness reduction and compensatory channel expansion: a study of online and face-to-face sections of the same course'. International Journal of Distance Education Technologies - IJDET, vol. 9, no. 2, pp. 1-12. ISSN 1539-3100.

Kock, N., Verville, J. \& Garza, V. (2007) 'Media naturalness and online learning: findings supporting both the significant-and no-significant-difference perspectives', Decision Sciences Journal of Innovative Education, vol. 5, no. 2, pp. 333-355.

Koriat, A. \& Bjork, R. A. (2005) 'Illusions of competence in monitoring one's knowledge during study', Journal of Experimental Psychology: Learning, Memory, and Cognition, vol. 31, no. 2, pp. 187-194.

Kraut, R, Kiesler, S, Boneva, B, Cummings, J, Helgeson, V. \& Crawford, A. (2002) 'Internet paradox revisited', Journal of Social Issues, vol. 58, no. 1, pp. 49-74.

Kuo, P. H. (2016) 'Effects of synchronous web-based instruction on students' thinking styles and creativity', Eurasia Journal of Mathematics, Science \& Technology Education, vol. 12, no. 3, pp. 609-619.

Lauterman, T. \& Ackerman, R. (2014) 'Overcoming screen inferiority in learning and calibration', Computers in Human Behavior, vol. 35, pp. 455-463.

Lyons, A., Reysen, S. \& Pierce, L. (2012) 'Video lecture format, student technological efficacy, and social presence in online courses', Computers in Human Behavior, vol. 28, no. 1, pp. $181-186$.

Mader, C. \& Ming, K. (2015) 'Videoconferencing: a new opportunity to facilitate learning', The Clearing House: A Journal of Educational Strategies, Issues and Ideas, vol. 88, no. 4, pp. $109-116$.

Maldonado, J. G., et al., (2001) 'Personality, sex and communication via Internet', Anuario de Psicologia, vol. 32, no. 2, pp. 51-62.

Marquart, M., et al., (2016) 'Instructional strategies for synchronous components of online courses', in Creating Teacher Immediacy in Online Learning Environments, ed. S. D’Agustino, IGI Global, Hersley, PA, USA, pp. 188-212.

McKenna, K. Y. A., Green, A. S. \& Gleason, M. J. (2002) 'Relationship formation on the Internet: what's the big attraction?', Journal of Social Issues, vol. 58, pp. 9-32.

McKenna, K. Y. A., et al., (2007) Ameliorating Social Anxiety through Online Interaction, Unpublished manuscript, Beer-Sheva, Israel, Ben-Gurion University.

Paas, F., Renkl, A. \& Sweller, J. (2003) 'Cognitive load theory and instructional design: recent developments', Educational Psychologist, vol. 38, no. 1, pp. 1-4.

Paretti, M. C., McNair, L. D., Holloway-Attaway, L. (2007) 'Teaching technical communication in an era of distributed work: a case study of collaboration between U.S. and Swedish students', Technical Communication Quarterly, vol. 16, no. 3, pp. 327-353.

Redpath, L. (2012) 'Confronting the bias against on-line learning in management education', Academy of Management Learning \& Education, vol. 11, no. 1, pp. 125-140.

Reychav, I., Warkentin, M. \& McHaney, R. (2015) 'Exploring effects of media type and delivery technology on facilitating critical thinking among college students', Journal of Educational Technology Systems, vol. 44, no. 1, pp. 22-35.

Rhodes, M. G. \& Castel, A. D. (2008) 'Memory predictions are influenced by perceptual information: evidence for metacognitive illusions', Journal of Experimental Psychology: General, vol. 137 , no. 4 , pp. $615-625$. 
Sacco, D. F. \& Ismail, M. M. (2014) 'Social belongingness satisfaction as a function of interaction medium: face-to-face interactions facilitate greater social belonging and interaction enjoyment compared to instant messaging', Computers in Human Behavior, vol. 36, no. 359-364.

Schwartz, D. G. (2007) 'Integrating knowledge transfer and computer-mediated communication: categorizing barriers and possible responses', Knowledge Management Research and Practice, vol. 5, no. 4, pp. 249-260.

Sebastianelli, R., Swift, C. \& Tamimi, N. (2015) 'Factors affecting perceived learning, satisfaction, and quality in the online MBA: a structural equation modeling approach', Journal of Education for Business, vol. 90, no. 6, pp. 296-305.

Selwyn, N. (2014) Digital Technology and the Contemporary University: Degrees of Digitization, London, Routledge.

Shea, P., et al., (2001) 'Measures of learning effectiveness in the SUNY Learning Network', Online Education, vol. 2, pp. 31-54.

Sidi, Y., Ophir, Y. \& Ackerman, R. (2016) 'Generalizing screen inferiority-does the medium, screen versus paper, affect performance even with brief tasks?', Metacognition and Learning, vol. 11, no. 1, pp. 15-33.

Sidi, Y., et al., (2017) 'Understanding metacognitive inferiority on screen by exposing cues for depth of processing', Learning and Instruction, https://doi.org/10.1016/j.learninstruc.2017. 01.002, http://www.sciencedirect.com/science/article/pii/S0959475217300178

Tapsis, N. \& Tsolakidis, K. (2015) 'Educational communication in virtual worlds and videoconference', International Journal of Emerging Technologies in Learning, vol. 10, pp. 64-69.

Voorn, R. J. \& Kommers, P. A. (2013) 'Social media and higher education: introversion and collaborative learning from the student's perspective', International Journal of Social Media and Interactive Learning Environments, vol. 1, no. 1, pp. 59-73.

Warkentin, M. E., Sayeed, L. \& Hightower, R. (1997) 'Virtual teams versus face-to-face teams: an exploratory study of a web-based conference system', Decision Sciences, vol. 28, no. 4, pp. 975-996.

Weiser, O, Blau, I. \& Eshet-Alkalai, Y. (2016) 'The role of pedagogy, media, and students' personality in synchronous learning: Comparing face-to-face and video conferencing participation', in Proceedings of the 10th annual International Technology, Education and Development Conference- INTED2016, Valencia, Spain, pp. 5005. doi: 10.21125/inted. 2016.0226 